\title{
Comparison of Coronally Advanced Flap with Semilunar Coronally Repositioned Flap with Sutures for the Treatment of Gingival Recession
}

\author{
Sweta RL Rana ${ }^{1}$, Surendra Man Shrestha ${ }^{2}$, Ameena Pradhan ${ }^{2}$ \\ ${ }^{1}$ Dental Department, Nepalese Army Institute of Health Sciences, Kathmandu, Nepal. ${ }^{2}$ People's \\ Dental College and Hospital, Kathmandu, Nepal
}

\begin{abstract}
Introduction: The surgical correction of shallow gingival recession by coronally advanced flap (CAF) and its variant semilunar coronally repositioned flap (SLF) offers the advantage of a single surgical site, less patient discomfort and predictable root coverage with good colour match. This study aims to compare and evaluate the predictability and reliability of the two types of flaps. Methods: In 20 Miller's Class I recession defects, 10 sites each were treated with either SLF or CAF. Recession height, recession width, clinical attachment loss, width of keratinized gingiva, Plaque Index and Gingival Index were assessed at baseline, 1, 3 and 6 months. The intra-group comparison was done using paired t-test and the inter-group comparison using independent t-test with statistical $\mathrm{p}$ value set at $<0.05$. Results: Average root coverage seen with Group I (SLF) at 1 month was $51.67 \%$ and with Group II (CAF) was $62.5 \%$ and at 6 months the root coverage was $42.5 \%$ for both the groups. In both Groups, statistically significant changes in recession width and recession height were seen from baseline to 6 months. No statistically significant difference was seen between the two groups at any time period. Conclusions: The coronally advanced flap is predictable in the treatment of gingival recessions. However the semilunar flap with additional stabilizing suture may also be beneficial in treating gingival recessions and further research is needed in this technique.
\end{abstract}

Keywords: coronally advanced flap; gingival recession; root coverage; semilunar flap

\section{INTRODUCTION}

Gingival recession is defined as the location of the gingival margin apical to cemento-enamel junction ${ }^{1}$. It is the exposure of the root surface by an apical shift in position of the gingival margin. The main etiology is toothbrush trauma or inflammatory conditions ${ }^{2}$. American Academy of Periodontology $y^{3}$ has stated that surgical correction of gingival recession is indicated for better aesthetics, reduction of root hypersensitivity and/or susceptibility to root caries when an unfavorable contour of the gingival margin limits proper plaque control and fails to respond to adequate oral hygiene measures. One of the periodontal plastic surgical procedures for the treatment include pedicled or advanced flaps.. The selection of a technique depends on the defect anatomy and

Correspondence: Sweta RL Rana, Dental Department, Nepalese Army Institute of Health Sciences, Chaauni, Kathmandu, Nepal. Email: sweta.rl.rana@gmail.com 
on the patient's demands. For Miller's Class I and II gingival recessions ${ }^{4}$, the coronally advanced flap has been shown to be predictable since 1926 as described by Norberg 5 . However later Tarnow in $1986^{13}$ reported a modification of the coronally advanced flap, the semilunar coronally repositioned flap technique with the advantages of lack of tension on the displaced flap, no vestibular shortening and cosmetically unchanged papillae proximal to the tooth. However, the flap may not be stable as it is not sutured.

The comparison of these two flaps have not been studied in Nepalese population and the feasibility and predictability of the semilunar flap with sutures is less well known. The aim of this study was to study and compare the results of both the techniques in the Nepalese population presenting in a tertiary level hospital.

This was a prospective comparative study done in the Department of Periodontology and Implantology, People's Dental College and Hospital (PDCH) from January to December 2012. Ethical approval was taken from the institutional review board and written consent from each of the patient. Total 20 patients with Miller's Class I labial/ buccal recession of 1-3 $\mathrm{mm}$ depth in maxillary anteriors and premolars were enrolled in the study. Other inclusion criteria included good systemic health, no use of medication known to interfere with periodontal health or healing, and no contraindication for periodontal surgery; sulcus probing depth $0-3 \mathrm{mms}$, adequate zone of attached gingiva and tooth vitality. The exclusion criteria included thin gingival biotype, restorations and caries, cervical abrasions, malaligned teeth, occlusal interferences, poor oral hygiene and noncompliance, high frenal attachment, smoking or tobacco chewing habit. Patients were divided into two groups of each into Group I for gingival recession defects treated with Semilunar Coronally Repositioned Flap (SLF) and Group II for gingival recession defects treated with Coronally Advanced Flap (CAF). Convenient sampling was done. A set proforma was used at baseline and recall visits to record changes in clinical parameters. Mouth mirror and UNC 15 periodontal probe were used to measure the clinical parameters. Demographic variables assessed included age and gender while the clinical variables assessed at baseline and post-operatively at 1 , 3 and 6 months were Oral hygiene index ${ }^{6}$, Plaque index ${ }^{6}$, Gingival index ${ }^{6}$ with Probing depth (PD) at 3 and 6 months.

The outcome variables were Recession Width (RW) from the greatest mesiodistal dimension of the gingival recession defect, Recession Height $(\mathrm{RH})$ : distance from CEJ to gingival margin, Width of keratinized gingiva (WKT) from distance between the most apical point of the gingival margin to mucogingival junction, Clinical attachment loss (CAL) from CEJ to the bottom of the sulcus. The calculation of root coverage \% was assessed as Pre-operative $\mathrm{RH}-$ Post operative RH $\times 100 \%$.

Surgical procedure-After taking the proforma with proper history taking and clinical examination, initial case preparation included ultrasonic scaling and root planning, oral hygiene instructions with Modified Stillman's brushing technique and repeated scaling and root planning after 1 week. Twenty cases were selected which were divided into two groups Group I (Semilunar flap) and Group II (Coronally advanced flap). 
Group I SLF- A split-thickness flap was raised under local anesthesia. A semilunar external bevel incision was given directed coronally following the curvature of the gingival margins $3 \mathrm{~mm}$ from the crest of interdental gingiva. A split thickness sulcular incision extending to the semilunar incision was given carefully to elevate a partialthickness flap. Root planing was done with Gracey curettes and ultrasonic instruments and any labial prominence of the tooth was altered. Root conditioning was done with citric acid $\mathrm{pH} 1$ for 3-5 minutes ${ }^{7}$.A partial-thickness flap distally up to the middle of the interdental papilla, leaving behind $3 \mathrm{~mm}$ of the papilla coronally. Vertical incisions were extended to mucogingival junction. A partial thickness flap mesial and distal to the recession defect, followed by a full thickness flap coronal to the recession defect up to $4-5 \mathrm{~mm}$ over the alveolar bone was raised with a periosteal elevator. Then a partial-thickness flap was raised again apical to the full thickness flap from the mucogingival junction. After flap elevation, root planning with Gracey curettes and ultrasonic scalers and root conditioning
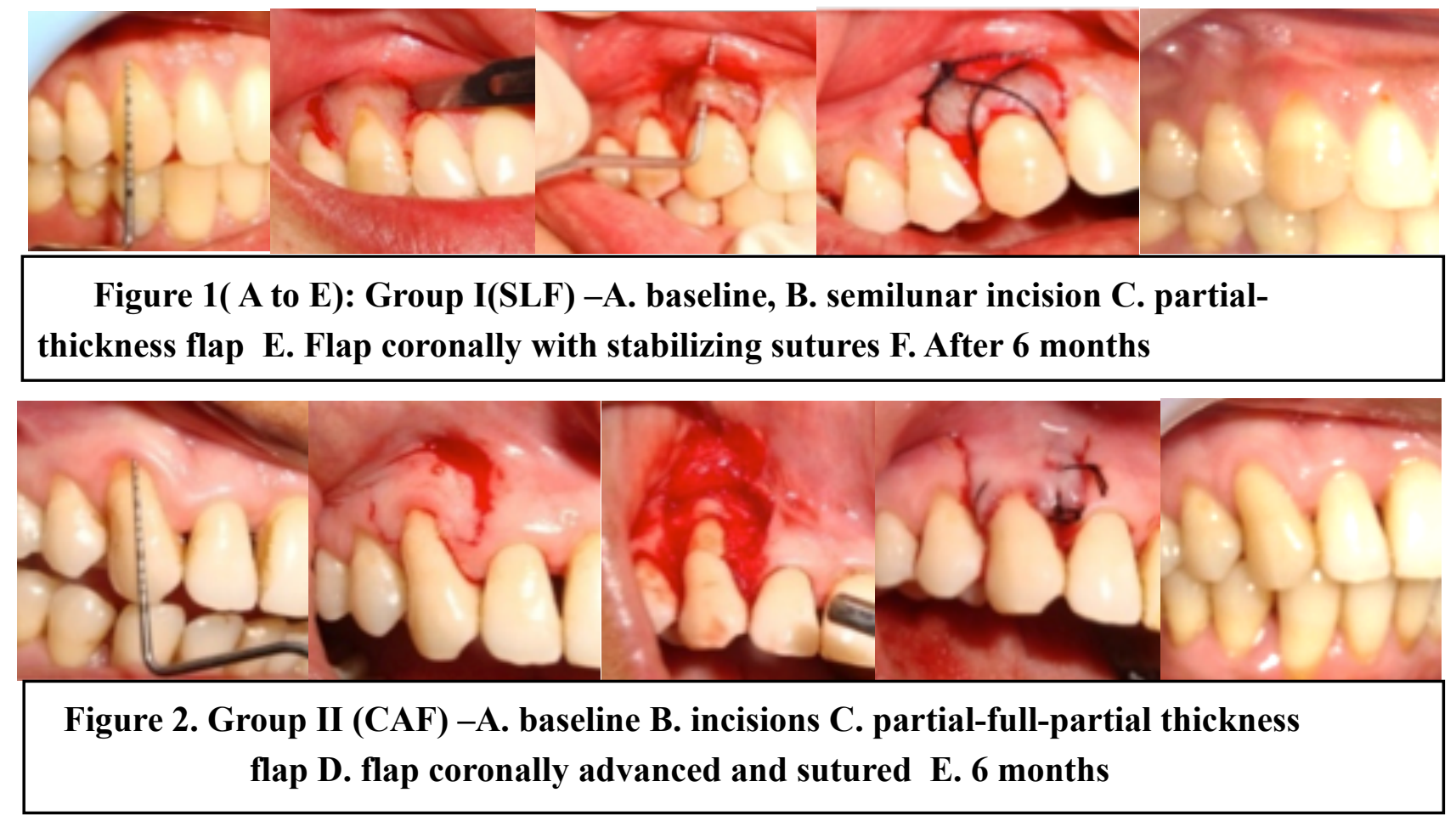

was raised and advanced $1 \mathrm{~mm}$ coronal to CEJ and pressed with moist gauze for 5 minutes to stabilize it. Additional stabilizing horizontal periosteal mattress suture was placed. Tinfoil and periodontal pack (Coe pack) was placed for 1 week.

Group II CAF- Under local anesthesia, horizontal partial thickness incisions were given $1 \mathrm{~mm}$ coronal to CEJ mesially and with citric acid was done. The area was thoroughly irrigated with normal saline. The interdental papilla mesial and distal to the flap was then deepithelialized. The flap was moved $1 \mathrm{~mm}$ coronal to CEJ and pressed with wet gauze for 5 minutes. Interrupted sutures were placed over the vertical incisions with 4-0 silk suture and sling suture was placed to anchor 
the flap in position, followed by Tinfoil and periodontal dressing.

Post- operative instructions-For both groups, for the first post-operative day, the patients were advised to take soft diet, avoid hot food or beverages, avoid any mechanical trauma to the site, avoid drinking from a straw, not to touch the area or rinse vigorously. The patients were explained on why the periodontal dressing was placed and to avoid removing it for a week. They were asked to visit the hospital in case of any emergency or discomfort or if the pack was dislodged. They were advised to rinse with $10 \mathrm{ml}$ of $0.2 \%$ chlorhexidine mouthwash twice daily for 2 weeks. Capsule Amoxicillin (Perimox) 500 mg TDS for 5 days and tablet Ibuprofen (Brufen) $400 \mathrm{mg}$ TDS for 3 days were prescribed. Patients were recalled after one week for removal of periodontal pack and sutures. They were recalled every month postsurgery for review and scaling.

\section{RESULTS}

Twenty maxillary Miller's Class I recession defects in 1 central incisor, 1 lateral incisor, 11 canines, 7 premolars were treated. The intragroup comparison using paired t-test for Group I showed statistically significant changes in gingival recession width from baseline to 1 month $(\mathrm{p}=0.03)$ and baseline to 6 months $(\mathrm{p}=0.04)$; and in recession height from baseline to 6 months $(\mathrm{p}=0.03)$. No other difference in clinical parameters was statistically significant.

For Group II, significant changes in recession width were seen from baseline to 1 month $(\mathrm{p}=0.02)$ and from baseline to 6 months $(\mathrm{p}=0.03)$; and in recession height from baseline to 1 month $(\mathrm{p}<0.01)$ and from 1 to 3 months and from baseline to 6 months $(\mathrm{p}=0.02)$. Statistically significant differences were also seen in width of keratinized tissue from baseline to 6 months $(\mathrm{p}=0.03)$ and $\mathrm{CAL}$

Table 1. Distribution of mean differences at baseline and 6 months for both groups

\begin{tabular}{|c|c|c|c|c|}
\hline Variable & Group & Baseline & 6 months & $P$ value \\
\hline \multirow[t]{2}{*}{ RW } & $\operatorname{SLF}(n=10)$ & $3.50 \pm 0.94$ & $2.65 \pm 1.31$ & \multirow[t]{2}{*}{0.53} \\
\hline & $\operatorname{CAF}(n=10)$ & $3.50 \pm 0.75$ & $2.27 \pm 1.34$ & \\
\hline \multirow[t]{2}{*}{ RH } & $\operatorname{SLF}(n=10)$ & $1.85 \pm 0.34$ & $1.15 \pm 0.82$ & \multirow[t]{2}{*}{0.89} \\
\hline & $\operatorname{CAF}(n=10)$ & $1.85 \pm 0.58$ & $1.10 \pm 0.84$ & \\
\hline \multirow[t]{2}{*}{ WKT } & $\operatorname{SLF}(n=10)$ & $4.75 \pm 1.18$ & $5.15 \pm 0.94$ & \multirow[t]{2}{*}{0.29} \\
\hline & $\operatorname{CAF}(n=10)$ & $5.00 \pm 0.94$ & $5.60 \pm 0.94$ & \\
\hline \multirow[t]{2}{*}{ CAL } & $\operatorname{SLF}(n=10)$ & $2.35 \pm 0.67$ & $1.55 \pm 0.98$ & \multirow[t]{2}{*}{1.00} \\
\hline & $\operatorname{CAF}(n=10)$ & $1.55 \pm 0.98$ & $1.55 \pm 1.01$ & \\
\hline \multirow[t]{2}{*}{ PI } & $\operatorname{SLF}(n=10)$ & $0.68 \pm 0.20$ & $0.79 \pm 0.32$ & \multirow[t]{2}{*}{0.86} \\
\hline & $\operatorname{CAF}(n=10)$ & $0.59 \pm 0.31$ & $0.76 \pm 0.44$ & \\
\hline \multirow[t]{2}{*}{ GI } & $\operatorname{SLF}(n=10)$ & $0.49 \pm 0.20$ & $0.61 \pm 0.30$ & \multirow[t]{2}{*}{0.73} \\
\hline & $\operatorname{CAF}(n=10)$ & $0.44 \pm 0.24$ & $0.56 \pm 0.33$ & \\
\hline
\end{tabular}




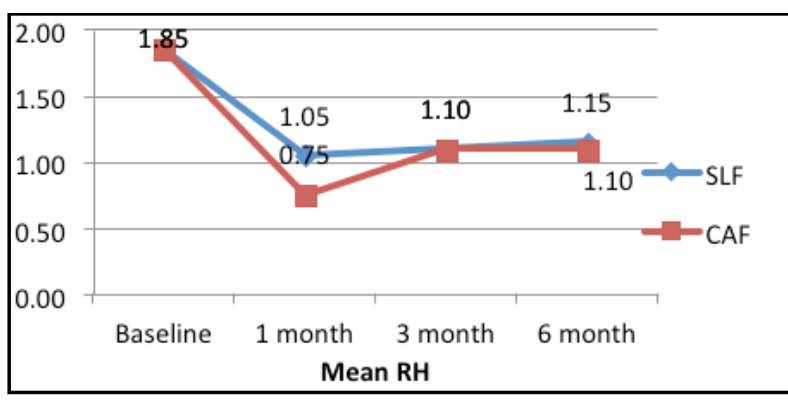

Figure 3. Differences in RH between Group I and II

from 3 to 6 months $(p=0.01)$ and from baseline to 6 months $(\mathrm{p}=0.006)$. Plaque index changed significantly from baseline to 6 months. There was no statistically significant difference in other parameters from baseline to 1,3 or 6 months.

Inter-group comparison using independent ttest (Table1, fig.3) showed no statistically significant difference in any of the clinical variables. At 1 month, mean root coverage was $51.67 \%$ with group I and $62.5 \%$ with group II. At 6 months, the root coverage was $42.5 \%$ for both groups. Complete root coverage at 1 month was seen in 2 cases (20\%) of group I and 3 cases $(30 \%)$ of group II which reduced to 1 case $(10 \%)$ in both groups at 6 months.

\section{DISCUSSION}

The mean root coverage of CAF (Group II) was $62.5 \%$ at 1 month. Lins et $\mathrm{al}^{8}$ have shown similar root coverage of $60 \%$ while better results have been reported by various authors $^{9-10 .}$ American Academy of Pediatrics ${ }^{11}$ reported success rates of 50-98\% (mean 78\%) and that $90 \%$ or greater coverage was achieved $39 \%$ of the time.

The factors affecting the success of CAF are the baseline recession depth, amount of keratinized tissue ${ }^{12}$; adjacent papillae width and height and flap thickness bigger than 1 $\mathrm{mm}^{13}$ and tobacco smoking ${ }^{14}$. The more coronal the level of the gingival margin after suturing, the greater the probability of complete root coverage ${ }^{15}$. In this study, gingival recessions up to $3 \mathrm{~mm}$ with adequate keratinized tissue were treated in nonsmokers. The flap was placed $1 \mathrm{~mm}$ passively post-surgically coronal to CEJ. Minimal flap tension does not influence recession reduction in the treatment of shallow recessions ${ }^{16}$. The thickness of the gingival tissue was measured by translucency of probe and not with transgingival probing or ultrasonic device. This may have been one factor that influenced the outcome.

According to Santana et $\mathrm{al}^{17}$, the differences in the results might be associated with differences in case selection and treatment protocol used. The difference in this study compared to study by Santana et $a 1^{17}$ were the lack of use of rotary instruments, root conditioning, placement of periodontal dressing for 1 week, less number of sutures and resumption of brushing after 2 weeks. Other factors may be soft tissue ablation, vestibular depth and difference in oral hygiene maintenance by the patient. Rocuzzo et al ${ }^{18}$ stated that the variability in studies could depend on factors such as the selection and magnitude of the defects, the location of the recession, the mean initial depth and operator skill.

However, the results of CAF deteriorated to $42.5 \%$ at 6 months. The plaque scores were significantly higher which may indicate the inability of the patient to maintain proper plaque control. Pini Prato et al ${ }^{19}$ showed a recurrence of $39 \%$ in gingival recession 
defects after 14 years and attributed it to the resumption of traumatic toothbrushing habits.

For SLF(Group I), the root coverage was $51.67 \%$ at 1 month and $42.5 \%$ at 6 months. Santana et $\mathrm{al}^{17}$ who showed a mean root coverage of $41.78 \% \quad$ root coverage .Bittencourt ${ }^{20}$ in 2007 used microsurgical techniques and fibrin glue adhesive and found root coverage of $90.1 \%$. The microsurgical technique might have improved the handling of thin and delicate soft tissues and more sensitive detection of root coverage in shallow defects ${ }^{17}$. Also in SLF, root coverage may not be uniform especially at the margins due to the greater dimension of the donor tissue than the recipient site which may cause instability of the flap. Santana et al ${ }^{17}$ also reported a lack of stability in root coverage might be due to the apical pull of the contracted wound at the area of the semilunar horizontal incision. In this study there was a deterioration of the stability of the flap at 6 months. This may be due to the increase in plaque and gingival index at 6 months, which was not statistically but may be clinically significant. Proper oral hygiene maintenance and brushing technique may be crucial for follow up.

\section{CONCLUSION}

Both the flap procedures were equally predictable for root coverage of shallow gingival recessions. Long-term follow up studies with larger sample size are needed on coronally advanced flap and semilunar flap with sutures, if possible with microsurgical aids, histological evidence of attachment gain and more sensitive methods of measuring the defect and tissue dimensions and flap tension.

\section{REFERENCES}

1. The American Academy of Periodontology. Glossary of Periodontal Terms, $4^{\text {th }}$ ed. Chicago: The American Academy of Periodontology; 2001.

2. Oates TW, Robinson M, Gunsolley JC. Surgical Therapies for the Treatment of Gingival Recession. A Systematic Review. Ann Periodontol. 2003;8(1): 303-20. http://dx.doi.org/10.1902/annals. 2003.8.1.303

3. American Academy of Periodontology (AAP), Consensus report: Mucogingival therapy. Ann Periodontol 1996;1:702-6.

4. Takei HH, Azzi RR, Han TJ. Periodontal plastic and esthetic surgery. In: Newman MG, Takei HH, Klokkevold PR, Carranza FA. Clinical Periodontology, $10^{\text {th }}$ ed. India: Reed Elsevier: 2006. p.1014-15.

5. Cohen ES. Surgical Basics. In: Cohen ES. Atlas of Cosmetic and Reconstructive periodontal surgery, $3^{\text {rd }}$ ed. USA: BC Decker: 2007. p.10.

6. Spolsky VW. Epidemiology of gingival and periodontal disease. In: Newman MG, Carranza FA, Clinical Periodontology, $8^{\text {th }}$ ed. India: Hartcourt Asia:1996.p. 67-8

7. Carranza FA, Takei HH, Cochran DL. Reconstructive periodontal surgery. In:Newman MG, Takei HH, Klokkevold PR, Carranza FA. Clinical Periodontology, $10^{\text {th }}$ ed. India: Reed Elsevier: 2006. p.974

8. Lins LHS, De Lima AFM, Sallum AW. Root coverage: Comparison of coronally positioned flap with or without titaniumreinforced barrier membrane. J Periodontol. 2003;74:168. http://dx.doi.org/10.1902/jop. 2003.74.2.168 
9. Allen EP, Miller PD. Coronal positioning of existing gingiva. Short-term results in the treatment of shallow marginal tissue recession. J Periodontol. 1989;60:316-19. http://dx.doi.org/10.1902/jop.1989.60.6.316

10. DeSanctis M, Zucchelli G. Coronally advanced flap: a modified surgical approach for isolated recession type defects. Three-year results. J Clin Periodontol. 2007;34:262-68. http:// dx.doi.org/10.1111/j.1600-051x.2006.01039.x

11. Research, Science and Therapy Committee of the American Academy of Periodontology. Informational Paper: Oral Reconstructive and Corrective Considerations in Periodontal Therapy. J Periodontol. 2005;76(9):1588-1600. http:// dx.doi.org/10.1902/jop.2005.76.9.1588

12. Neiri M, Rotundo R, Franchesi D, Cairo F, Cortellini P, Pini Prato G. Factors Affecting the Outcome of the Coronally Advanced Flap Procedure: A Bayesian Network Analysis. J Periodontol. 2009;80(3):405-10. http://dx.doi.org/10.1902/jop.2009.080146

13. Saletta D, PiniPrato G, Pagliaro U, Baldi C, Mauri M, Nieri M. Coronally Advanced Flap procedure: is the interdental papilla a prognostic factor for root coverage? J Periodontol. 2001;72:760-66. http:// dx.doi.org/10.1902/jop.2001.72.6.760

14. Chambrone L, Sukekava F, Araujo MG, Pustiglioni FE, Chambrone LA, Lima LA. Root coverage procedures for the treatment of localised recession-type defects. Cochrane Database of Systematic Reviews. $2009 ; 2$. ht t p ://dx.doi.org / 10.1002/14651858.cd007161.pub2

15. Pini Prato GP, Baldi C, Nieri $M$, Franseschi D, Cortellini P, Clauser C et al. Coronally Advanced Flap: The Post-
Surgical Position of the Gingival Margin Is an Important Factor for Achieving Complete Root Coverage. J Periodontol. 2005;76:713-22. http://dx.doi.org/10.1902/ jop.2005.76.5.713

16. Pini Prato G, Pagliaro U, Baldi C, Nieri M, Saletta D, Cairo F et al. Coronally Advanced Flap procedure for root coverage. Flap with tension versus flap without tension: a randomized controlled clinical study. J Periodontol. 2000;71:188-201. http://dx.doi.org/ 10.1902/jop.2000.71.2.188

17. Santana RB, Mattos CML, Dibart S. A clinical comparison of two flap designs for coronal advancement of the gingival margin- semilunar versus coronally advanced flap. J ClinPeriodontol 2010;37:651-58. http://dx.doi.org/10.1111/j. 1600-051x.2010.01582.x

18. Rocuzzo et al. Periodontal plastic surgery for treatment of localized gingival recessions: A systematic review. J Clin Periodontol. 2002;29:178-94. http:// dx.doi.org/10.1034/j.1600-051x.29.s3.11.x

19. Piniprato G, Rotundo R, Franceschi D, Cairo F, Cortellini P, Nieri M. Fourteenyear outcomes of coronally advanced flap for root coverage: follow-up from a randomized trial. J Clin Periodontol. 2011;38:715-20. http://dx.doi.org/10.1111/j. 1600-051x.2011.01744.x

20. Bittencourt S, Ribeiro EP, Sallum EA, Sallum AW, Nociti FH Jr, Casati MZ. Root surface biomodification with EDTA for the treatment of gingival recession with a semilunar coronally repositioned flap. J Periodontol. 2007;9:1695-1701. http:// dx.doi.org/10.1902/jop.2007.060507 